\title{
Automated measurement system for detecting carbonation depth: image-processing based technique applied to concrete sprayed with phenolphthalein
}

\author{
N. Giulietti ${ }^{1}$, P. Chiariotti ${ }^{1 *}$, G. Cosoli ${ }^{1}$, A. Mobili ${ }^{2}$, G. Pandarese ${ }^{1}$, F. Tittarelli ${ }^{2}$, G. M. Revel ${ }^{1}$ \\ ${ }^{1}$ Department of Industrial Engineering and Mathematical Science (DIISM), \\ Università Politecnica delle Marche, 60131, Ancona, Italy. \\ ${ }^{2}$ Department of Materials, Environmental Sciences and Urban Planning (SIMAU), \\ Università Politecnica delle Marche - INSTM Research Unit, 60131, Ancona, Italy.
}

*Corresponding author: p.chiariotti@univpm.it (Paolo Chiariotti).

\begin{abstract}
This paper aims at discussing an automated measurement system for detecting carbonation depth in concrete sprayed with phenolphthalein. Image processing and Convolutional Neural Networks strategies are exploited to accurately separate the carbonated and non-carbonated areas and to remove those aggregates on the carbonation front that could bring to a wrong evaluation of the carbonation depth. Very strong correlation $\left(\mathrm{R}^{2}\right.$ $>0.98$ ) is found between results provided by the proposed approach and the method suggested by the EN 13295 standard. The expanded uncertainty (coverage factor $\mathrm{k}=2$ ) of this novel approach is $0.08 \mathrm{~mm}$. ANOVA analysis performed in multi-operator tests proved that the highest source of uncertainty is the measurement system, which, on the other hand, is robust to changes in the operator performing the measurement.
\end{abstract}

\section{Keywords}

Carbonation depth measurement system, Concrete durability, Image-processing, Convolutional Neural Networks 


\section{Introduction}

Durability of concrete is defined as its ability to resist weathering action, chemical attack, abrasion, or any other process of deterioration, by retaining the original form, quality, and serviceability when concrete itself is exposed to a certain environment [1].

In the late $20^{\text {th }}$ century, an increasing number of reinforced concrete structures showed major deterioration due to durability problems, causing huge costs for repair and rehabilitation. This has also become an economic issue, with estimated direct and indirect costs of $3-4 \%$ of gross national product in developed countries, connected to maintenance and repair operations [2].

One of the main causes of degradation is the carbonation of concrete. This is considered a critical problem, particularly in those regions characterized by a warm and relatively humid environment [3]. The carbonation of cement paste lowers the $\mathrm{pH}$ of the pore solution, thus contributing in depassivating steel reinforcements and in making them prone to corrosion. The $\mathrm{pH}$ value of non-carbonated cement-based material is approximately 13, but it moves around 9 when carbon dioxide diffuses inside the material itself. This occurs since calcium hydroxide $\left(\mathrm{Ca}(\mathrm{OH})_{2}\right)$ contained in the pore solution, reacting with carbon dioxide, is converted into calcium carbonate $\left(\mathrm{CaCO}_{3}\right)$ [4], with a significant carbonation rate when $\mathrm{RH}$ ranges between $45-95 \%$. In this way, the passive layer protecting the steel rebars is damaged and steel starts to corrode if it gets in contact with moist air [5]. The initiation of reinforcement corrosion is the main responsible for shortening the service life of reinforced concrete structures (RCS) [6,7]. Therefore, monitoring RCS is of utmost importance to prevent irreversible damages that may also end up in structural failure.

The test used for determining carbonation depth is regulated by the EN 13295 standard [5]. This standard suggests spraying a phenolphthalein solution on the target to highlight the presence of carbonated/noncarbonated areas. The phenolphthalein solution changes its colour in relation to the $\mathrm{pH}$ of the material: in the non-carbonated part of the specimen, where concrete has still a highly alkaline behaviour $(\mathrm{pH}>9)$, a purplered coloration is obtained, whereas in the carbonated area of the specimen, where $\mathrm{pH}<9$, no colour change is observed [8]. The standard describes a procedure in which the operator is asked to manually measure the carbonation depth $\left(\mathrm{d}_{\mathrm{k}}\right)$, i.e. "the average distance, measured in $\mathrm{mm}$, from the surface of the concrete or mortar where the $\mathrm{CO}_{2}$ has reduced the alkalinity of the hydrated cement to an extent such that an indicator solution based on phenolphthalein remains colourless", by using rulers, callipers, etc. 
However, it should be underlined that, even if this method is easy to perform, it suffers from subjectivity, due to operator's experience, colours perception, and manual ability, low repeatability and low reproducibility. This paper aims at overcoming the aforementioned limits by discussing an automated and objective approach, based on machine vision, for measuring carbonation depth of concrete.

There are very few papers dealing with the automated detection of carbonation depth in scientific literature. Segura et al. [9] developed an automatic digital image-processing algorithm that filters the image of the specimen, after calibration and background removal, to enhance the contour of the carbonated area and hence calculate carbonation depth. The algorithm appears to be accurate and strongly correlated to manual measurements $\left(\mathrm{R}^{2}=0.96\right)$. Yet, the main drawback is that the heterogeneity of the specimen requires different thresholding/segmentation approaches when using direct sunlight illumination to separate the carbonated from the non-carbonated areas.

Choi et al. [10] developed an image-processing technique to automatically detect the carbonated region highlighted by phenolphthalein solution; their algorithm consists of two subsequent detection processes: an initial binarization followed by a convex hull operation. The algorithm seems to be quite robust, but unfortunately, no quantitative results on carbonation depth are provided.

Ruiz Madera [11] developed a dedicated vision system to take pictures in homogeneous light conditions and two different algorithms to detect the carbonated area in concrete specimens. The former is an imageprocessing based algorithm for image segmentation in the RGB space; the latter exploits neural networks and deterministic image-processing strategies to improve detection of carbonation depth; indeed, this coupled approach causes an improvement in accuracy of $20 \%$ with respect to the sole use of deterministic approaches. However, the use of neural networks seems to exceed the requirements for this application, which could be afforded in a simpler way. In fact, neural networks have a significant computational time and require the definition of proper parameters, whose value considerably affects the output, so that an imprecise setting could cause considerable measurement errors (also in terms of repeatability).

This paper presents a measurement system (hardware and software) targeted to the automated detection of carbonation depth in concrete specimens. Results obtained with the system have been compared to those performed by adopting the manual procedure defined in the EN 13295 standard. This comparison has been made in terms of carbonation depth values, repeatability and time consumption. Four different concrete 
compositions developed within the European project EnDurCrete (New Environmental friendly and Durable conCrete, integrating industrial by-products and hybrid systems, for civil, industrial and offshore applications) have been tested to prove the robustness of the system to concrete colour variation (e.g. due to the presence of carbon-based additions).

The paper is organised as follows: Section 2 discusses the preparation of the concrete specimens and the phenolphthalein test for measuring carbonation depth; Section 3 describes the developed automated measurement system, focusing both on its hardware and software parts; Section 4 reports the metrological characterisation of the automated system and the comparison with manual measurements carried out on different concrete mixes; finally, Section 5 reports the main conclusions on the performance evaluation of the developed automated algorithm.

\section{Materials and experimental methods}

\subsection{Preparation of concrete specimens}

A Portland blended cement was used to cast four concrete compositions ( 1 1, C2, C3, and C4). Limestone/quartz river sand $(0 / 4 \mathrm{~mm})$ was used as fine aggregate, whereas intermediate $(5 / 10 \mathrm{~mm})$ and coarse $(10 / 15 \mathrm{~mm})$ river gravels were used as coarse aggregates. Two polycarboxylate (PC)-based water reducers were used to reach the desired workability class (S5).

The reference concrete, labelled as $\mathrm{C} 1$, was produced with a cement content of $375 \mathrm{~kg} / \mathrm{m}^{3}$ and water/cement (w/c) ratio equal to 0.42 by weight. Aggregates were dosed at $48 \%$ for sand, $19 \%$ for intermediate gravel and $33 \%$ for coarse gravel, respectively, on the total aggregates volume. Three increasing percentages of carbonbased additions were added in order to change the colour of specimens, which from the lighter to the darker are identified as $\mathrm{C} 2, \mathrm{C} 3$, and $\mathrm{C} 4$, respectively.

The concrete batches were mixed in a concrete mixer by adding at first powder materials in the following order: aggregates, carbon-based addition, and cement (mixed for 2 minutes). Afterwards, water was added and mixed for 3 minutes, then PC admixtures were incorporated to reach the same workability class (S5) and mixed for 15 minutes.

Concretes were poured into cubic moulds of $10 \mathrm{~cm}$ per side and cured at a temperature (T) of $20 \pm 1{ }^{\circ} \mathrm{C}$ and a relative humidity $(\mathrm{RH})$ higher than $95 \%$ for 28 days. 


\subsection{Accelerated carbonation and phenolphthalein test}

After 28 days of curing, the concrete specimens were exposed to accelerated carbonation in an environmental test chamber (Figure 1) at $\mathrm{T}=21 \pm 1{ }^{\circ} \mathrm{C}, \mathrm{RH}=60 \pm 10 \%$ and $\mathrm{CO}_{2}$ concentration $=3 \pm 0.2$ vol.\% [12]. This $\mathrm{CO}_{2}$ concentration, much higher than the one suggested by the $\mathrm{EN} 13295$ standard (i.e. $\mathrm{CO}_{2}=1 \%$ ), was adopted to accelerate the carbonation process of the specimens.

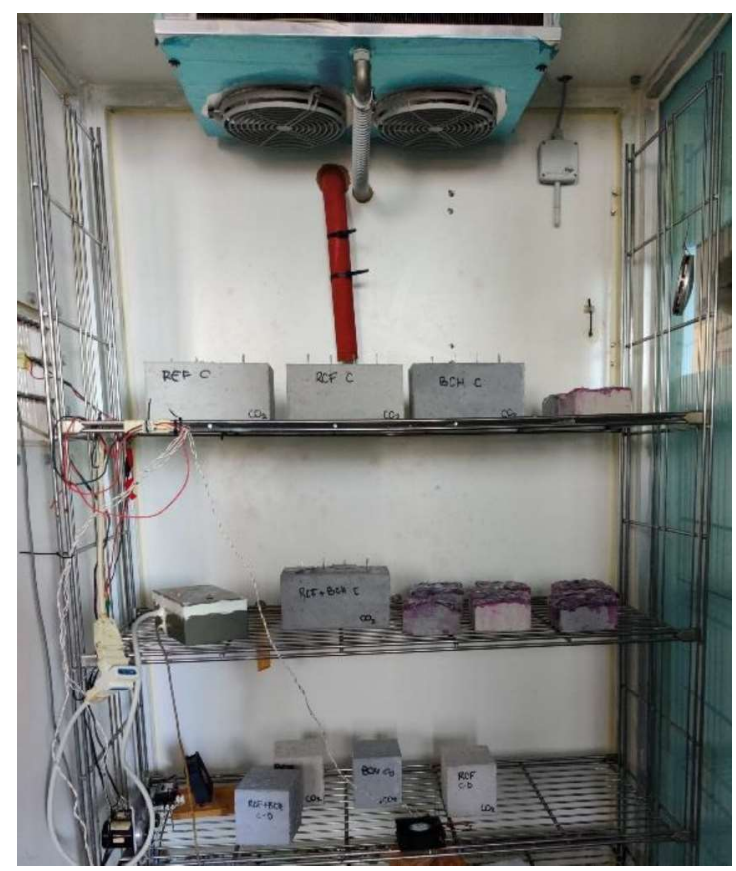

Figure 1 Environmental $\mathrm{CO}_{2}$ chamber hosting concrete specimens

The carbonation depth was measured on the specimens according to the EN 13295 standard at 7 days after the curing period. This operation was performed by cutting the specimens and treating the internal surface with $1 \%$ solution of phenolphthalein in alcohol. Indeed, the specimens (cubes) were split into two halves, internally sprayed with phenolphthalein solution, and pictures taken of the sprayed surfaces. The maximum carbonation depth $\left(\mathrm{d}_{\max }\right)$ was also measured, even if the standard requires to measure it only when the carbonation profile is irregular and $\mathrm{d}_{\mathrm{k}}>4 \mathrm{~mm}$. Manual measurements were performed using a Vernier calliper (accuracy \pm 0.01 $\mathrm{mm})$. 


\section{Automated measurement system for carbonation depth of concrete}

The automated measurement system discussed in this paper (Figure 2a) aims to objectively measure the carbonation depth on concrete specimens.

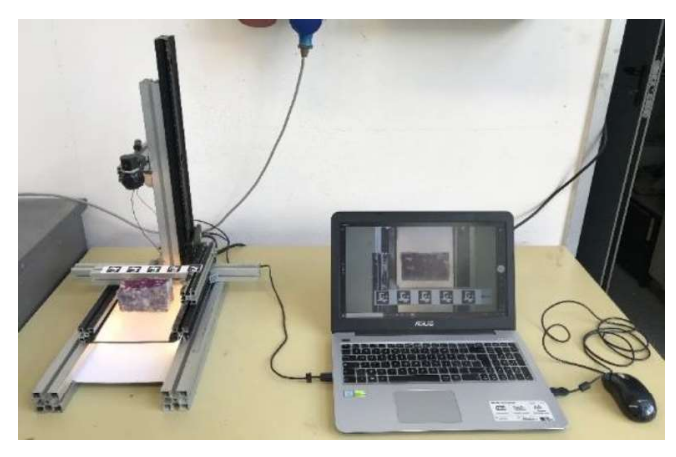

(a)

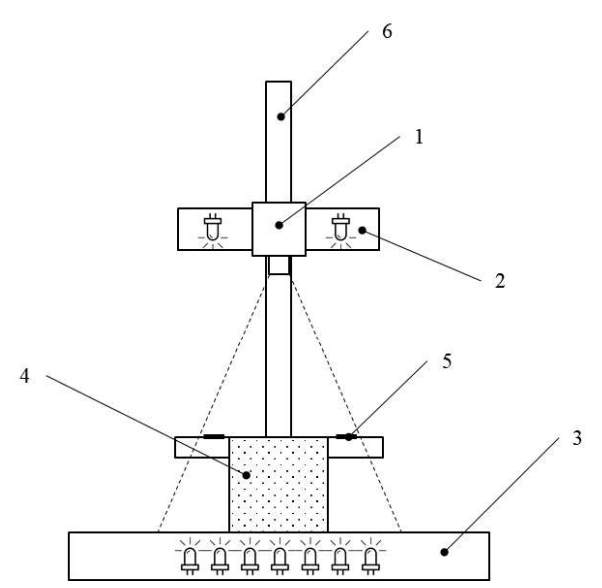

(b)

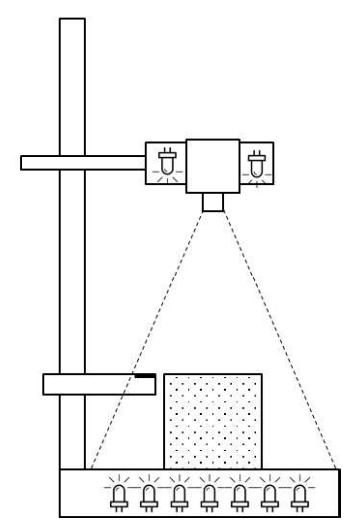

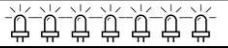

Figure 2 Measurement system setup for carbonation depth measurement system: overall setup (a) and detailed representation (b)

The measurement setup, excluding the specimen to be tested, consists of the following elements (Figure $2 \mathrm{~b}$ ):

- $\quad$ Camera (1) and diffuse illumination system (2): the camera is a standard full-HD (1920x1080 pixel) webcam with auto-focus capability. The choice of such a camera is to demonstrate the possibility of having accurate measurement results also with a low-cost device. Two slightly tilted (compared to the camera optical axis) LED strips covered with a diffusing panel were used for diffuse illumination.

- $\quad$ Bar with fiducial markers (5): five markers are placed on a bar whose height can be adjusted, with reference to the height of the specimen (4). The bar can slide on a dovetail guide (6). The positioning of the markers at the same height of the sprayed surface of the specimen makes it possible to perform a pixel-to-mm conversion. The markers adopted are squared markers targeted to be recognised by the Python OpenCV ArUco library $([13,14])$ and they are needed to perform an automated camera calibration [15];

- $\quad$ Back-light LED illumination plate (3): the homogeneous high-contrast background created by backlight illumination makes it possible to ease the detection of the external contour of the specimen. 

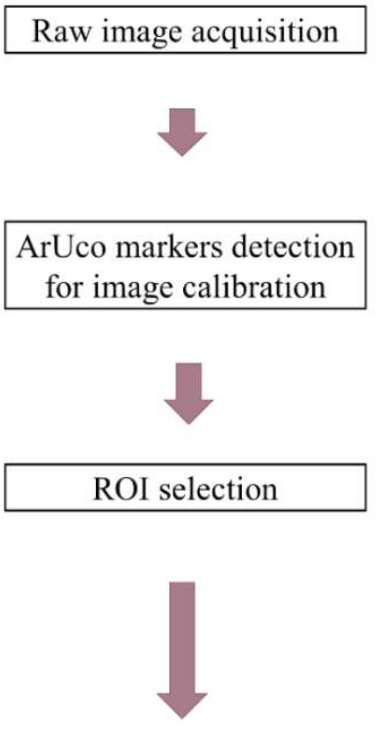

Specimen contour extraction

\section{Purple area identification}

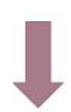

Carbonation depth $\left(\mathrm{d}_{\mathrm{k}}\right)$ and Maximum carbonation depth $\left(\mathrm{d}_{\max }\right)$

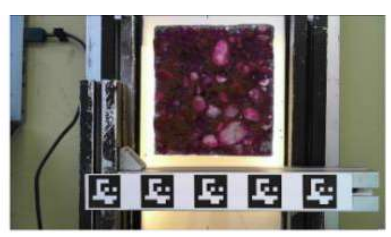

$\sqrt{1}$
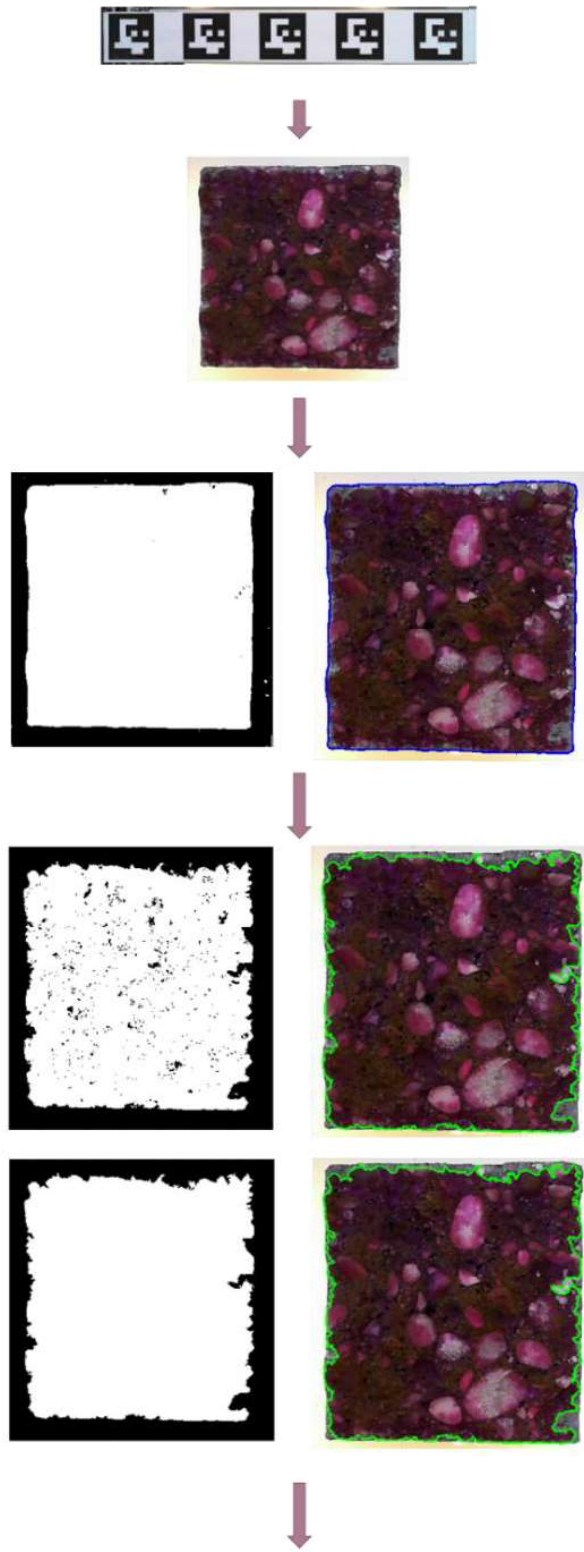

$d_{k}$

Figure 3 Workflow for measuring the carbonation depth of a concrete specimen sprayed with phenolphthalein

As for the measurement procedure, it consists in three main steps: a) once the specimen is positioned on the lighting plate with the sprayed surface facing the camera, b) the sliding bar is adjusted to have the markers at the same level of the target surface; c) the operations reported in Figure 3 are performed by a software 
specifically developed in Python programming language that exploits the OpenCV library [16]. More in details, once the raw image is acquired by the software, the processing algorithm performs the following operations:

- ArUco marker detection for image calibration: the script autonomously detects the 5 ArUco markers and measures, for each of them, the length of the sides of the markers in terms of pixels. Then, the average value of the 20 measured sides is calculated. Knowing that the side of each marker is $25 \mathrm{~mm}$, the pixel-to-mm conversion constant is obtained, and the picture is calibrated;

- ROI (Region-Of-Interest) selection: a ROI is extracted from the image acquired in order to exclude all the disturbing elements that are presents in the background of the picture;

- Specimen contour extraction: To ease the extraction of the specimen's contours (in Computer Vision contours are curves obtained by joining all the continuous points with similar intensity along the boundary of a target), a binarization of the image is usually recommended [16]; this step requires a proper selection of a threshold on the intensity values associated to the pixels of the image. The combined diffuse and back-light illumination adopted in the system makes it possible a smoother identification of two distinct areas in the histogram intensity values of the image: the darkest area of the specimen, on the left, and the lightest area of the background, on the right.

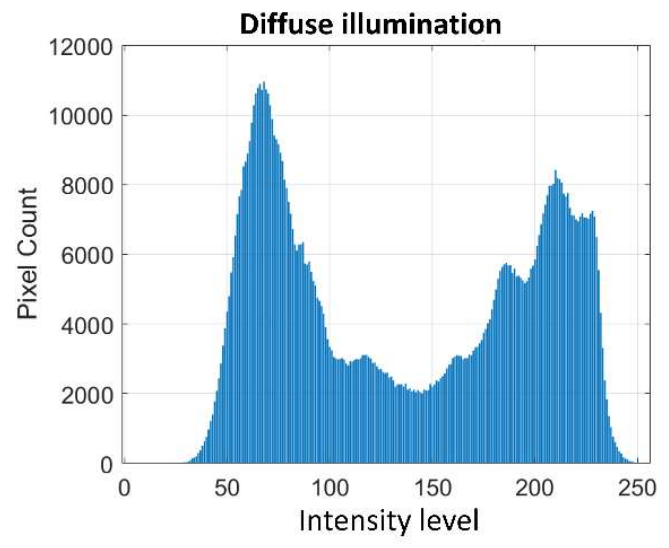

(a)

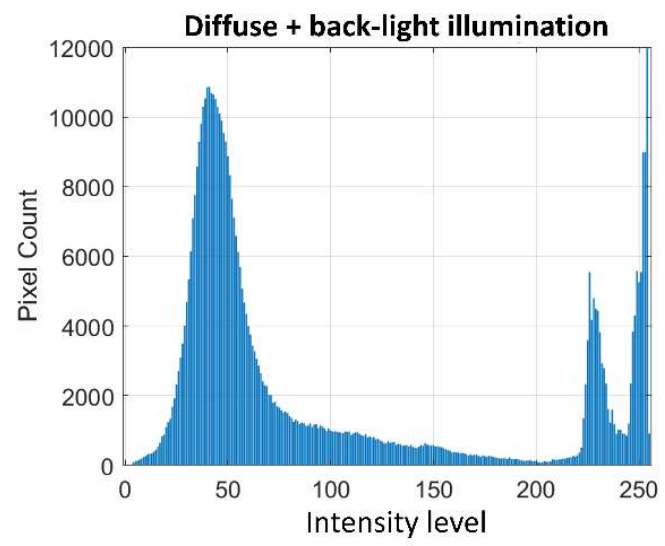

(b)

Figure 4 Histogram representation of pixel intensity level of specimen image: Comparison between diffuse (a) and diffuse plus back-light (b) illumination.

Figure 4 reports a comparison of the histogram representation of pixel intensity between a specimen illuminated by diffuse illumination (Figure 4a) and the same specimen illuminated via both diffuse 
and back-light illumination (Figure $4 \mathrm{~b}$ ). The wider separation between these two areas is well evident in the latter configuration. Indeed, this eases the identification of a proper pixel intensity threshold that brings to a correct separation of the specimen contour with respect to the background in the binarized image.

The length of this contour is the external perimeter of the specimen and the area within the contour represents the specimen overall surface area;

- Purple area identification: the purple contour representing the carbonation front is identified through a binary threshold on the HSV (hue, saturation, value) colour space. Contrarily to the RGB colour spaces, which codes colour through three channels, the HSV colour spaces, which separates luma, i.e. image intensity, from chroma, i.e. colour information, codes colour only by the hue channel; in fact, the other two channels express the saturation, from unsaturated (shades of grey) to fully saturated, and the brightness (value) of the colour. This justifies the use of the HSV colour space for colour-based segmentation. Indeed, processing the image in the HSV colour space makes it possible to widen the colour separation between the carbonated and the non-carbonated area, since those pixels belonging to the image region targeted to be considered non-carbonated will therefore fall into a specific range of hue, saturation and value.

The threshold ranges in the HSV colour space have been chosen by asking an operator expert in testing according to the EN 13295 standard, but not expert in computer vision, to analyse 24 different specimens through a dedicated graphical user interface (Figure 5). The set of 24 specimens was created by including specimens cast with the four concrete mixes in order to have different concrete and purple colour tone. The optimal thresholds in the HSV colour space have been identified as those producing the wider min-max intervals of Hue, Saturation and Value and guaranteeing a good quality label on the automatically thresholded images when revised by the expert.

As shown in Figure 6a, once thresholding in the HSV colour space is performed, the binarized image obtained is effective for isolating the contour of the non-carbonated area and thus for calculating the area within this contour. It is worth mentioning that aggregates within the contour are considered holes and properly filled to be included in the calculation of the overall non-carbonated area. 


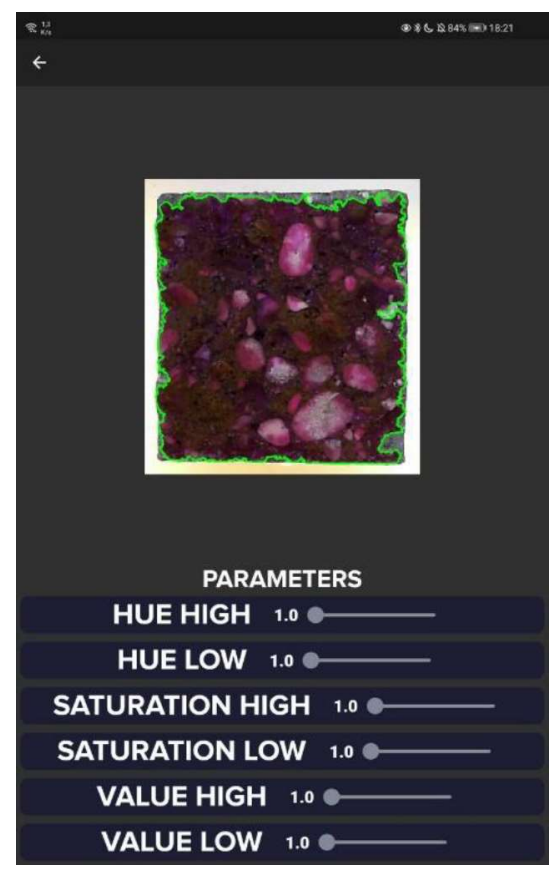

Figure 5 Graphic user interface adopted for interactive selection of the thresholds in the HSV colour space. The blue contour represents the specimen external perimeter, whereas the green contour represents the purple area detected

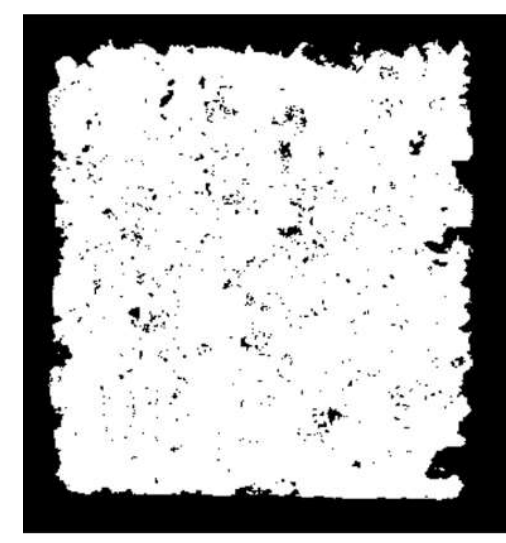

(a)

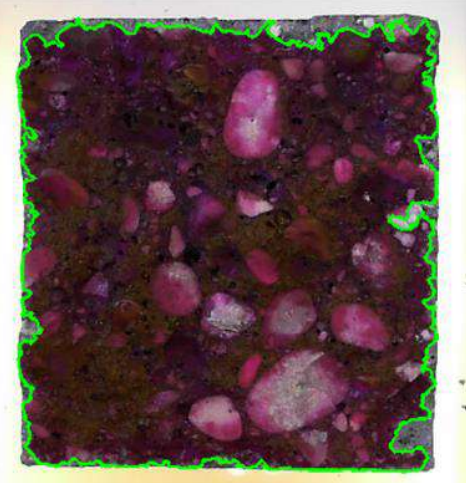

(b)

Figure 6 Binary image obtained through HSV range threshold (a), green biggest contour which well individuate non-carbonated area (b).

- Carbonation depth $\left(\mathrm{d}_{\mathrm{k}}\right)$ calculation: the EN 13295 standard recommends to perform the following steps to estimate the carbonation depth: a) identify five measurement points on each side of the sprayed surface of the specimen; b) measure carbonation depth with a ruler/calliper, rounded to the nearest 0.1 $\mathrm{mm}$, in correspondence of the five identified points; c) compute the average value on the five measures, 
rounded to the nearest $0.5 \mathrm{~mm}$; d) repeat the process for each side of the specimen and e) compute $d_{k}$ as the mean value of the depths calculated for each one of the target sides of the specimen.

The availability of the image of the specimen makes it possible to increase the statistical basis on which calculating the carbonation depth, since this value can be obtained as the ratio between the area of the carbonated zone and the perimeter of the same zone - see equation 1.

$$
\text { carbonation depth }[\text { pixel }]=\frac{\left(\text { carbonated area }\left[\text { pixel }^{2}\right]\right)}{(\text { perimeter }[\text { pixel }])}
$$

The area of the carbonated zone can be estimated by subtracting the area of the non-carbonated zone from the total area within the external contour of the specimen, according to equation 2 .

carbonated area $\left[\right.$ pixel $\left.^{2}\right]=$ total area $\left[\right.$ pixel $\left.^{2}\right]-$ non - carbonated area $\left[\right.$ pixel $\left.^{2}\right]$

The carbonation depth in dimensional units can be calculated by applying the pixel-to-mm conversion parameter according to equation 3 .

$$
\text { carbonation depth }[\mathrm{mm}]=\frac{(\text { carbonation depth }[\text { pixel }])}{(\text { pixel }- \text { to }-\mathrm{mm}[\text { pixel }])}
$$

- Maximum carbonation depth $\left(\mathrm{d}_{\max }\right)$ calculation: when the distribution of aggregates is dense over the specimen surface, they may likely lie on the carbonation front. If this is the case, since aggregates react differently to phenolphthalein and remain uncoloured, they can induce in misleading interpretation of $d_{\max }[10]$. On the one hand, a human operator could be able to discard aggregates in the calculation of the maximum carbonation depth; on the other hand, this choice is highly subjective, since it also relates to the colour-perception of each operator. To make the whole approach robust and highly objective, a dedicated classification process based on Convolutional Neural Network (CNN [17]) was developed. The VGG16 [18] classifier (Keras's implementation [19]) was trained by selecting ROIs containing/not containing aggregates (500 pictures of each type, divided between training and 
validation sets, with a ratio equal to 9:1). The classifier was then integrated in an algorithm that scans the specimen area horizontally and vertically, starting from the centre of gravity of the specimen face in order to find the maximum distance of the carbonation profile from the external contour; if an aggregate is present within the profile, the value is discarded.

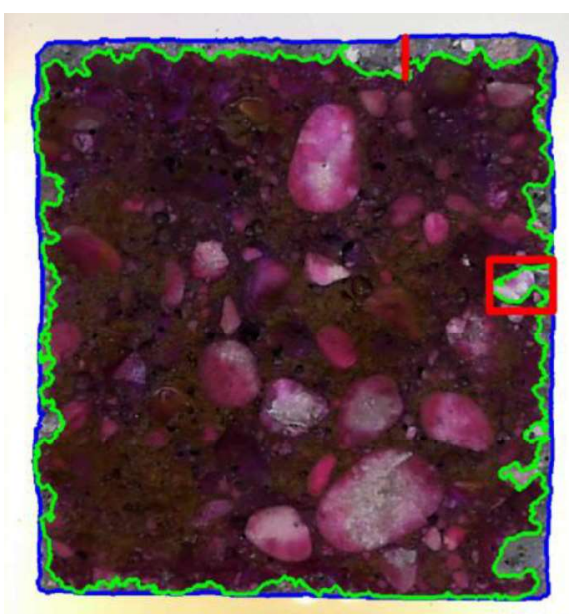

Figure 7 Dense aggregate detection (red square) and correction of the identified maximum carbonation value

An example of the output is reported in Figure 7, where the correct value of the maximum carbonation depth is identified by the red line. The red rectangle highlights the max depth that would have been identified if aggregates were not removed: this would result in a miscalculation of the maximum carbonation depth, which would result in $10.70 \mathrm{~mm}$ (overestimated value) with respect to $5.90 \mathrm{~mm}$ (correct value).

\section{Results and discussion}

\subsection{Metrological characterization}

The metrological performance of the measurement system was assessed in terms of repeatability and reproducibility[20]. The Type A uncertainty was assessed by taking 100 pictures of the same specimen while its angular position is slightly varying on the lighting plane for back-light illumination (i.e. rotating the specimen around the vertical axis perpendicular to the lighting plane). The reproducibility of the measurement system was assessed by asking 3 different operators to perform ten measurements each. It should be highlighted that the specimens used for the two analyses were different. This choice was undertaken to demonstrate the robustness of the approach. 
The distribution, normalised with respect to their mean value, related to the values measured in the intraoperator analysis is reported in Figure 8. The Type A uncertainty associated to the measurement is estimated to be $0.04 \mathrm{~mm}$. If considering a coverage factor $k=2$, an expanded uncertainty value of $0.08 \mathrm{~mm}$ is identified.

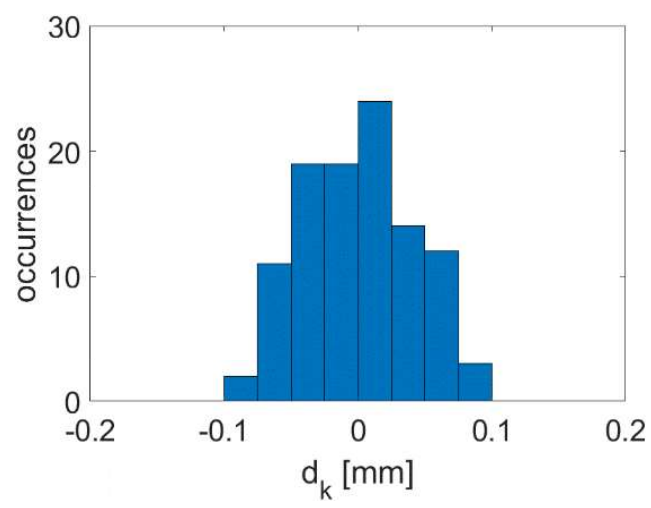

Figure 8 Distribution normalised with respect to the mean value of carbonation depth values measured on 100 images by the same operator

Data belonging to the inter-operator tests were analysed performing an ANOVA single factor analysis. Table 1 and Table 2 report, respectively, the Variance analysis for each operator and the results of the ANOVA test.

Table 1 Inter-operator test: operator performance on ten measurements

\begin{tabular}{lrrrr}
\hline \multicolumn{1}{c}{ Groups } & Count & \multicolumn{1}{c}{$\begin{array}{c}\text { Sum } \\
{[\mathrm{mm}]}\end{array}$} & $\begin{array}{c}\text { Average } \\
{[\mathrm{mm}]}\end{array}$ & $\begin{array}{c}\text { Variance } \\
{\left[\mathrm{mm}^{2}\right]}\end{array}$ \\
\hline Operator 1 & 10 & 32.97 & 3.29 & 0.0021 \\
Operator 2 & 10 & 32.80 & 3.28 & 0.0018 \\
Operator 3 & 10 & 32.84 & 3.28 & 0.0014 \\
\hline
\end{tabular}

Table 2 ANOVA table of inter-operator test

\begin{tabular}{|c|c|c|c|c|c|c|c|}
\hline Source of Variation & $\begin{array}{c}\text { Sum of } \\
\text { Squares } \\
{\left[\mathrm{mm}^{2}\right]}\end{array}$ & $\begin{array}{c}\text { Degree } \\
\text { of } \\
\text { freedom }\end{array}$ & $\begin{array}{c}\text { Variances } \\
{\left[\mathrm{mm}^{2}\right]}\end{array}$ & $F$ & $\begin{array}{c}\text { Standard } \\
\text { Deviations } \\
{[\mathrm{mm}]}\end{array}$ & $P$-value & $F$ crit \\
\hline Between Groups & 0.0015 & 2 & 0.0007 & 0.4184 & 0.02 & 0.6622 & 3.3541 \\
\hline Within Groups & 0.0479 & 27 & 0.0017 & & 0.04 & & \\
\hline Total & 0.0494 & 29 & & & & & \\
\hline
\end{tabular}

From the ANOVA analysis, it is clear that the null-hypothesis is verified. Moreover, the reproducibility variance is quite small $\left(0.0007 \mathrm{~mm}^{2}\right)$ if compared with the repeatability one $\left(0.0017 \mathrm{~mm}^{2}\right)$. This means, on the 
one hand, that the main amount of variation is due to the algorithm itself; on the other hand, that the algorithm is quite robust to position changes of the specimen over the lighting table. Indeed, in performing inter-operator tests, each operator was asked to remove the specimen from the lighting table and to place it again over the table to perform the measurement. This sequence was intended to randomize the way the specimen could have been framed by the camera. Figure 9 reports the variation of the specimen centre point (a) over the image and the rotation angle of the specimen around the camera optical axis (b). Hence, despite a translational variation of $15 \mathrm{~mm}$ and $9 \mathrm{~mm}$ (horizontal and vertical variations of the centre of the specimen) and an angular variation of $\pm 3^{\circ}$ in the positioning of the specimen, the algorithm can calculate the carbonation depth of the specimen with the same uncertainty identified in the inter-operator test. The main source of uncertainty is therefore the one associated to the algorithm itself, and it turns out to be $\mathrm{U}=0.08 \mathrm{~mm}$ (expanded uncertainty calculated with coverage factor $k=2$ ).

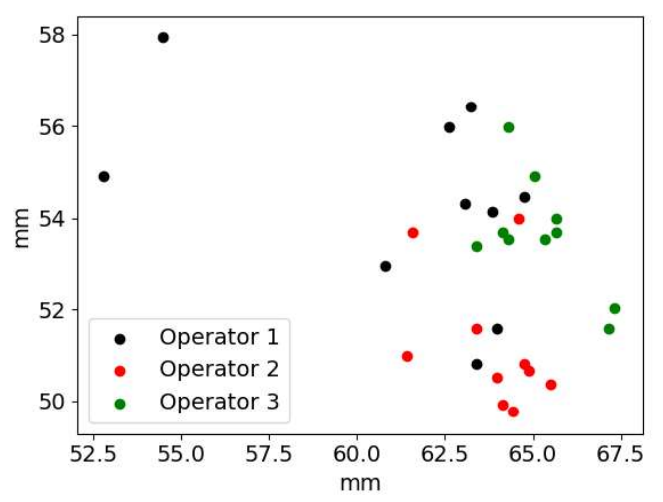

(a)

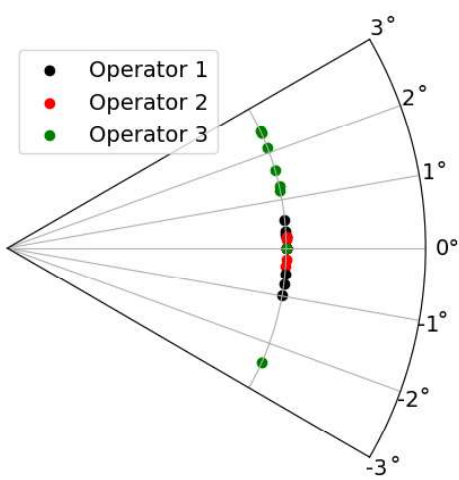

(b)

Figure 9 Variation of the specimen position over the lighting table during the inter-operator test: location of the centre of the specimen obtained as distance from the origin of the ROI of the image (a); rotation angle of the specimen around the camera optical axis (b)

\subsection{Comparison with manual measurement results}

Table 3 reports the carbonation depth values measured on the four different specimens after 7 days of accelerated carbonation test.

Measurement were performed both with the method recommended by the EN 13295 (manual measurement), and the new developed automated system. Results are reported both in terms of non-approximated values and with $0.5 \mathrm{~mm}$ accuracy, this latter value being the resolution recommended by the EN 13295 standard. 
Table 3 Carbonation depth [mm] results obtained with calliper and automated algorithm

\begin{tabular}{|c|c|c|c|c|c|c|c|c|c|c|c|c|c|c|c|c|}
\hline & \multicolumn{4}{|c|}{ C1 } & \multicolumn{4}{|c|}{ C2 } & \multicolumn{4}{|c|}{$\mathrm{C} 3$} & \multicolumn{4}{|c|}{$\mathrm{C} 4$} \\
\hline & \multicolumn{2}{|c|}{$d_{k}$} & \multicolumn{2}{|c|}{$d_{\max }$} & \multicolumn{2}{|c|}{$\mathbf{d}_{\mathrm{k}}$} & \multicolumn{2}{|c|}{$d_{\max }$} & \multicolumn{2}{|c|}{$d_{k}$} & \multicolumn{2}{|c|}{$d_{\max }$} & \multicolumn{2}{|c|}{$d_{k}$} & \multicolumn{2}{|c|}{$d_{\max }$} \\
\hline & 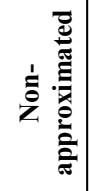 & 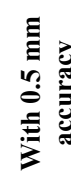 & 总 & 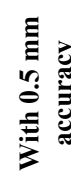 & 竞言 & 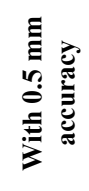 & 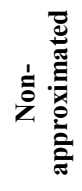 & 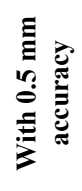 & 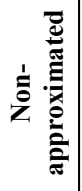 & 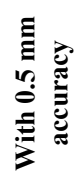 & 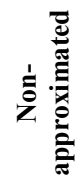 & 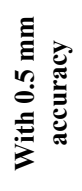 & 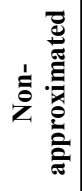 & 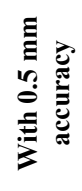 & 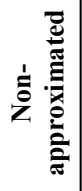 & 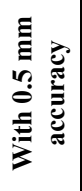 \\
\hline Calliper & 1.51 & 1.50 & 6.20 & 6.00 & 2.93 & 3.00 & 8.20 & 8.00 & 2.06 & 2.00 & 7.90 & 8.00 & 2.01 & 2.00 & 7.60 & 7.50 \\
\hline $\begin{array}{l}\text { Automated } \\
\text { algorithm }\end{array}$ & 1.42 & 1.50 & 6.24 & 6.00 & 2.86 & 3.00 & 8.10 & 8.00 & 2.01 & 2.00 & 8.23 & 8.00 & 2.18 & 2.00 & 7.71 & 7.50 \\
\hline
\end{tabular}

It is evident that the automated method well complies to the EN 13295 requirements: if rounding to $0.5 \mathrm{~mm}$ accuracy, the carbonation depth values of the automated system perfectly match those measured manually. Concerning maximum carbonation values, it can be noticed that the automated system well matches the calliper results. Indeed, if comparing the raw $\mathrm{d}_{\mathrm{k}}$ and $\mathrm{d}_{\max }$ results provided by the two methods (Figure 10), a correlation coefficient $\mathrm{R}^{2}=0.96$ is obtained, indicating a very strong correlation between the two approaches. The linear fitting of the $d_{k}$ values shows a small offset of about $0.03 \mathrm{~mm}$, apparently indicating an overestimation of results given by the automated system. This could be due, for instance, to the different calculation methods adopted by the two approaches, since the whole carbonation profile is considered in the automated system, whereas just 5 points are analysed in the manual measurement; this could explain the absence of offset in the one-shot measurement for evaluating the $\mathrm{d}_{\max }$ value. If rounding data to the nearest value with $0.5 \mathrm{~mm}$ resolution, as suggested by the EN 13295 standard, a perfect correlation is found, since the two approaches provide the same values for $d_{k}$ and $d_{\max }$.

It should be highlighted that the automated algorithm is also robust to changes in concrete colour, ranging from bright - reference $\mathrm{C} 1$ - to dark (because of carbon-based additions) - C2, C3, C4. 


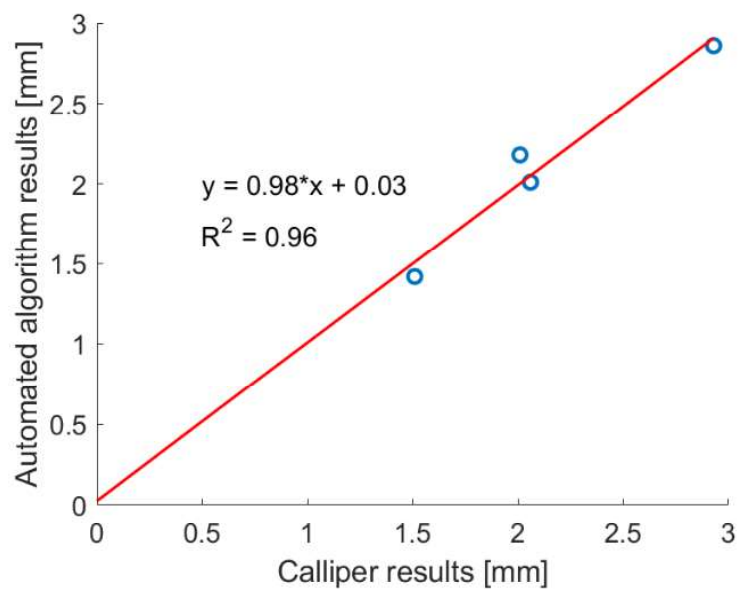

(a)

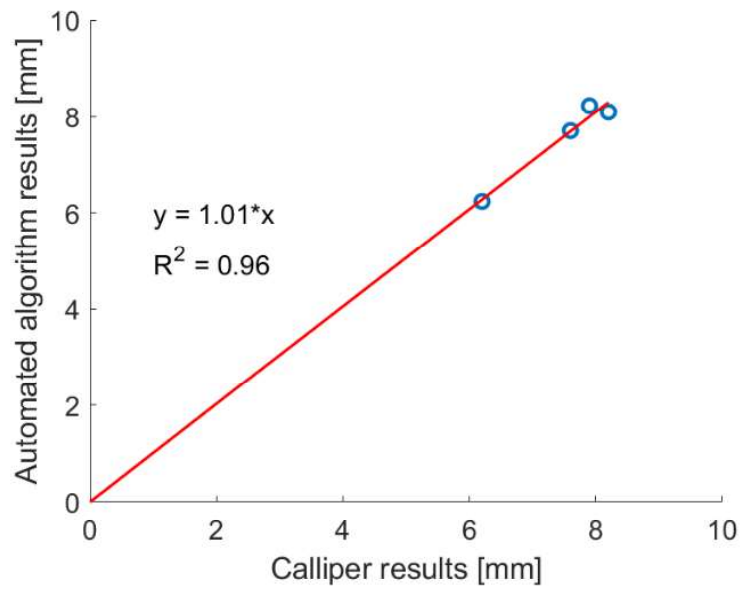

(b)

Figure 10 Correlation between automated algorithm and calliper results: $d_{k}(a)$ and $d_{\max }$ (b) values

As measurement time is concerned, it is worthy to note that the manual procedure requires time not only for the measurement itself, but also for evaluating all the different case studies reported in the standard (presence of a dense aggregate lying within the carbonation front, side length lower than $3 \mathrm{~cm}$, etc.), whereas these are all implemented in the automated algorithm. With the manual method, the measurement requires approximately $240 \mathrm{~s}$ per specimen (considering an expert operator), whereas the automated algorithm takes just 5 s per specimen (Intel Core i5-6600 CPU $3.30 \mathrm{GHz}$ machine). Therefore, the time saving with the automated method is of about $98 \%$.

\section{Conclusions}

An automated measurement system for detecting carbonation depth in concrete specimens has been proposed and discussed in this paper. By exploiting machine vision and Convolutional Neural Networks, the system is able to automatically calculate the carbonation depth $\left(\mathrm{d}_{\mathrm{k}}\right)$ and the maximum carbonation depth $\left(\mathrm{d}_{\max }\right)$ of a specimen, rejecting the eventual presence of aggregates lying on the carbonation front. The system proved to be accurate (estimated expanded uncertainty $U=0.08 \mathrm{~mm}$ ) and robust to changes in the operator performing the measurement. Moreover, the approach also proved to be robust to changes in the colour of the concrete specimen analysed. Correlation analysis performed with the method suggested by the EN 13295 standard proved the efficacy of the whole method, with great time saving (approximately -98\%). 


\section{Acknowledgements}

This research activity was carried out within the EnDurCrete (New Environmental friendly and Durable conCrete, integrating industrial by-products and hybrid systems, for civil, industrial and offshore applications) project, funded by the European Union's Horizon 2020 research and innovation programme under grant agreement $n^{\circ} 760639$.

\section{References}

[1] Durability of Concrete, (n.d.). https://www.concrete.org/topicsinconcrete/topicdetail/durability of concrete? search=durability of concrete (accessed June 3, 2020).

[2] C. Monticelli, M. Criado, S. Fajardo, J.M. Bastidas, M. Abbottoni, A. Balbo, Corrosion behaviour of a Low Ni austenitic stainless steel in carbonated chloride-polluted alkali-activated fly ash mortar, Cem. Concr. Res. 55 (2014) 49-58. https://doi.org/10.1016/j.cemconres.2013.09.014.

[3] S.H. Han, W.S. Park, E.I. Yang, Evaluation of concrete durability due to carbonation in harbor concrete structures, Constr. Build. Mater. 48 (2013) 1045-1049. https://doi.org/10.1016/j.conbuildmat.2013.07.057.

[4] S.C. Paul, B. Panda, Y. Huang, A. Garg, X. Peng, An empirical model design for evaluation and estimation of carbonation depth in concrete, Meas. J. Int. Meas. Confed. 124 (2018) 205-210. https://doi.org/10.1016/j.measurement.2018.04.033.

[5] EN 13295:2004 Products and systems for the protection and repair of concrete structures - Test methods - Determination of resistance to carbonation, n.d. http://store.uni.com/catalogo/en-132952004.

[6] L. Bertolini, B. Elsener, P. Pedeferri, R. Polder, Corrosion of Steel in Concrete: Prevention, Diagnosis, Repair, Wiley Blackwell, Weinheim, 2005. https://doi.org/10.1002/3527603379.

[7] F. Tittarelli, A. Mobili, C. Giosuè, A. Belli, T. Bellezze, Corrosion behaviour of bare and galvanized steel in geopolymer and Ordinary Portland Cement based mortars with the same strength class exposed to chlorides, Corros. Sci. 134 (2018) 64-77. https://doi.org/10.1016/j.corsci.2018.02.014.

[8] M. Collepardi, The New Concrete, Tintoretto, 2010. https://www.encosrl.it/the-new-concrete/.

[9] I. Segura, M. Molero, S. Aparicio, A. Moragues, Measurement of the degraded depth in cementitious 
materials by automatic digital image processing, Meas. Sci. Technol. 21 (2010).

https://doi.org/10.1088/0957-0233/21/5/055103.

[10] J. Il Choi, Y. Lee, Y.Y. Kim, B.Y. Lee, Image-processing technique to detect carbonation regions of concrete sprayed with a phenolphthalein solution, Constr. Build. Mater. 154 (2017) 451-461. https://doi.org/10.1016/j.conbuildmat.2017.07.205.

[11] C.C. Ruiz Madera, Implementación de algoritmos de inteligencia artificial y procesamiento digital de imágenes en la determinación de la profundidad de carbonatación en estructuras de concreto, (2018).

[12] A. Mobili, A. Belli, C. Giosuè, T. Bellezze, F. Tittarelli, Comportamento a corrosione di armature zincate in malte geopolimeriche e cementizie a parità di classe di resistenza, Metall. Ital. 109 (2017) $47-50$.

[13] F.J. Romero-Ramirez, R. Muñoz-Salinas, R. Medina-Carnicer, Speeded up detection of squared fiducial markers, Image Vis. Comput. 76 (2018) 38-47. https://doi.org/10.1016/j.imavis.2018.05.004.

[14] S. Garrido-Jurado, R. Muñoz-Salinas, F.J. Madrid-Cuevas, R. Medina-Carnicer, Generation of fiducial marker dictionaries using Mixed Integer Linear Programming, Pattern Recognit. 51 (2016) 481-491. https://doi.org/10.1016/j.patcog.2015.09.023.

[15] A. Valmorbida, M. Mazzucato, M. Pertile, Calibration procedures of a vision-based system for relative motion estimation between satellites flying in proximity, Meas. J. Int. Meas. Confed. 151 (2020) 107161. https://doi.org/10.1016/j.measurement.2019.107161.

[16] Learning OpenCV: Computer Vision with the OpenCV Library - Gary Bradski, Adrian Kaehler Google Libri, (n.d.).

https://books.google.it/books?hl=it\&lr=\&id=seAgiOfu2EIC\&oi=fnd\&pg=PR3\&dq=Learning+OpenC $\mathrm{V}:+$ Computer+Vision + with + the + OpenCV+Library\&ots=hUK4djdEM9\&sig=U7Xfx4mLfstfJe2eoX APL0Cn-fI\#v=onepage\&q=Learning OpenCV\%3A Computer Vision with the OpenCV Library\&f=false (accessed November 26, 2019).

[17] A Comprehensive Guide to Convolutional Neural Networks — the ELI5 way, (n.d.). https://towardsdatascience.com/a-comprehensive-guide-to-convolutional-neural-networks-the-eli5way-3bd2b1164a53 (accessed November 26, 2019).

[18] K. Simonvan, A. Zisserman, Very Deep Convolutional Networks for Large-Scale Image Recognition, 
(n.d.).

https://www.researchgate.net/publication/265385906_Very_Deep_Convolutional_Networks_for_Lar ge-Scale_Image_Recognition (accessed May 28, 2020).

[19] Keras: the Python deep learning API, (n.d.). https://keras.io/ (accessed June 3, 2020).

[20] BIPM - Guide to the Expression of Uncertainty in Measurement (GUM), (2017).

http://www.bipm.org/en/publications/guides/gum.html. 